Original article

\title{
Expression and detection of oestrus in cattle
}

\author{
Michael G. DiskiN*, Joseph M. SREENAN \\ Animal Reproduction Department, Teagasc, Athenry, Co. Galway, Ireland
}

(Received 2 June 2000; accepted 28 August 2000)

\begin{abstract}
For herds using AI heat detection rate and calving rate are the two major determinants of compactness of calving, of the proportion of cows that fail to conceive in a defined breeding season. Numerous factors affect the expression of heat including, housing arrangement, floor surface, feet and leg problems and status of herd mates. The number of mounts a cow receives increases with the number of cows that are in heat simultaneously up to about 3-4 cows in heat. Generally, cows that are themselves in heat, coming into heat or were recently in heat are most likely to mount a cow that is in heat. Cows that are at the mid-stages of their cycles (day 5 to about day 16) are least likely to mount a cow that is in heat and consequently could be termed "poor heat detectors". Similarly, cows that are pregnant show less interest in mounting other cows that are in heat. In smaller herds and as more cows become pregnant the likelihood of more than one cow being heat on any given day becomes less, consequently, making heat detection more difficult. The single most important factor affecting heat detection efficiency is that those responsible for checking for heat should fully understand the signs of heat and be fully committed to heat detection for as long as it is planned to use AI. Technological aids to improve heat detection include the use of tail paint, oestrous synchronisation, vasectomised bulls, pressure activated heat mount detectors, radio telemetric devices, pressure sensitive mount count devices and pedometers. As herd size increases and labour become more expensive there will be a greater adoption of some of these technological aids.
\end{abstract}

\section{heat / detection / cattle}

Résumé - Manifestation et détection de l'œstrus chez les bovins. Dans les élevages où l'on utilise l'insémination artificielle (IA) les taux de détection des chaleurs et de mises bas sont les deux déterminants majeurs du rapprochement des mises bas et de la proportion de vaches qui ne conçoivent pas dans une période définie de reproduction. La manifestation des chaleurs est affectée par de nombreux facteurs incluant, la surface du sol, les problèmes de membres et de pieds et l'état des congénères. Le nombre de montes que subit une vache augmente avec le nombre de femelles en chaleurs simultanément, jusqu'à 3-4 vaches. En général, les vaches en chaleur, sur le point de l'être ou qui viennent de l'être sont moins propices à monter une autre femelle en chaleur. Les vaches qui sont en milieu de cycle (J5 à J16) ont peu de chance d'en monter une autre et pourraient donc, être dénommées « faible détectrices de chaleurs ». De façon similaire, les vaches gestantes montrent moins d'intérêt dans la monte que d'autres vaches en chaleurs. Dans les troupeaux plus petits et plus il y a de vaches gestantes, la probabilité pour que plus d'une vache arrive en chaleurs à un jour

* Correspondence and reprints

E-mail: mdiskin @ athenry.teagasc.ie 
donné, diminue donc, rendant ainsi la détection des chaleurs plus difficile. Le facteur le plus important affectant l'efficacité de la détection des chaleurs est que ceux qui en sont chargés interprètent parfaitement les manifestations de chaleurs et qu'ils soient pleinement engagés dans ce processus aussi longtemps que l'IA est planifiée. Les outils technologiques pour améliorer la détection des chaleurs incluent l'utilisation de peinture sur la queue, de synchronisation des cycles, de taureaux vasectomisés, de détecteurs de monte activés par pression, d'appareils de radiotélémétrie, d'appareils de comptage de montes sensibles à la pression et de podomètres. Avec l'augmentation de la taille des troupeaux et du coût du travail, il y aura une plus grande utilisation de ces aides technologiques.

chaleurs / détection / bovin

\section{INTRODUCTION}

Reproductive efficiency is a major factor affecting the production and economic efficiency of dairy and beef herds. For herds using AI, heat detection rate and calving rate are the two major determinants of compactness of calving, of the proportion of cows that fail to conceive in a defined 13-week breeding season (Tabs. I and II) and ultimately of the calving-to-calving interval. Heat detection is a time consuming repetitive chore that must be carried out up to 5-times a day each day for as long as AI is used. Heat detection rate, usually measured as submission rate, is hugely variable from herd-to-herd and between 30 and $70 \%$ of cows that exhibit heat are usually detected in heat by the stockman. The objective of this paper is to review physiological, management and environmental factors that affect the expression of oestrus and the technologies that have potential to improve heat detection rates.

\section{PHYSIOLOGICAL FACTORS OF OESTRUS}

\subsection{Endocrine control of oestrus}

During the course of the oestrous cycle, waves of follicular growth occur at regular intervals, with two to four distinct cohorts of follicles emerging together during each cycle. Each follicle wave has an inherent lifespan of 7-10 days as it progresses through emergence, selection, dominance and atresia or ovulation. The emergence of each new wave is stimulated by a transient (1-2 day) increase in FSH [1, 20, 24] with selection occurring during declining FSH concentration, and the dominant follicle then maintaining FSH at nadir concentrations until it either ovulates or succumbs to atresia, depending on the pattern of FSH secretion. The first or subsequent dominant follicle of the cycle is capable of producing sufficient oestrogen to induce oestrus and subsequently ovulate, if the corpus luteum is

Table I. The effect of different heat detection and conception rates on the $\%$ of the dairy herd that is pregnant at 45 days after onset of breeding season.

\begin{tabular}{llllll}
\hline & & \multicolumn{4}{c}{ Conception rate \% } \\
\cline { 3 - 5 } & & 60 & 50 & 40 & 30 \\
\hline \multirow{2}{*}{ Heat detection rate \% } & 90 & 96 & 91 & 83 & 71 \\
& 70 & 89 & 82 & 73 & 61 \\
& 50 & 76 & 68 & 59 & 48 \\
& 40 & 67 & 59 & 50 & 40 \\
\hline
\end{tabular}


Table II. The effect of different heat detection and conception rates on the $\%$ of the dairy herd that is non-pregnant after a 90 day breeding season.

\begin{tabular}{lccccc}
\hline & & \multicolumn{5}{c}{ Conception rate \% } \\
\cline { 3 - 5 } & & 60 & 50 & 40 & 30 \\
\hline \multirow{3}{*}{ Heat detection rate \% } & 90 & 4 & 9 & 17 & 29 \\
& 70 & 11 & 18 & 27 & 39 \\
& 50 & 24 & 32 & 41 & 52 \\
& 40 & 33 & 41 & 50 & 60 \\
\hline
\end{tabular}

lysed by exogenously administered $\mathrm{PGF}_{2 \alpha}$ [23]. Oestrogen, specifically oestradiol-17 $\beta$, is the primary signal to the hypothalamus that induces oestrus, but only in the absence of progesterone [26]. When progesterone reaches a threshold concentration early in the luteal phase, it can inhibit the occurrence of oestrus [26].

It appears that stressors which elevate blood concentration of cortisol are capable of delaying or blocking the preovulatory LH surge and affecting the expression of oestrus without altering pro-oestrous concentrations of blood oestradiol $17 \beta$ (see review by Stevenson [21]). Occurrence of oestrus seems to be an all-or-none phenomenon with the intensity of oestrous expression apparently not related to either dose or blood concentrations of oestradiol$17 \beta[4]$.

\subsection{Duration of oestrus}

The duration of the oestrous cycle averages 21 days in cows within a normal range of 18-26 days [13,28] and 20 days in heifers [8]. Published estimates of the duration of oestrus vary considerably. This variation is probably due in part to different criteria used to define oestrus (Tab. III).

Breaks or quiescent interludes in standing activity have also been observed [2, 15, 22]. O'Farrell observed that breaks in standing activity occurred in $30 \%$ of dairy cows at pasture while Stevenson et al. [22], using HeatWatch, recorded breaks with an average duration of 2.6 hours in $67 \%$ in beef heifers.

\subsection{Pattern of heat onset}

The onset of heat activity follows a distinct pattern, with greatest activity in the

Table III. Summary of the average duration of oestrus in cattle.

\begin{tabular}{llcc}
\hline Study & $\begin{array}{c}\text { Method of } \\
\text { observation }\end{array}$ & $\begin{array}{c}\text { Animal } \\
\text { category }\end{array}$ & $\begin{array}{c}\text { Average duration } \\
\text { (hours) }\end{array}$ \\
\hline Trimberger [25] & Observation & Dairy cows & 17.8 \\
O'Farrell [15] & Observation & Dairy cows & 8.8 \\
Dransfield et al. [6] & HeatWatch & Dairy cows & 7.1 \\
Xu et al. [29] & HeatWatch & Dairy cows & 8.6 \\
Mawhinney and Roche [12] & Observation & Beef cows & 12.8 \\
Trimberger [25] & Observation & Heifers & 15.3 \\
Mawhinney and Roche [12] & Observation & Heifers & 12.8 \\
Diskin 2000 (unpublished) & HeatWatch & Heifers & 14.5 \\
\hline
\end{tabular}


early morning and late evening. Data from this laboratory for dairy cows at pasture is presented in Table IV.

From this data we conclude that careful checking for heat in the early morning and late evening minimises the night interval and results in the detection of at least $70 \%$ of cows in heat. Three further checks during the day, at about 4-5 hour intervals, are required to detect $90 \%$ of the cows in heat.

\section{FACTORS AFFECTING THE EXPRESSION OF HEAT}

Numerous factors affect the expression of heat, the more important of which are briefly discussed.

\subsection{Housing arrangement}

For satisfactory expression of heat cows must have adequate space to allow cow-tocow interaction. If the stocking density is too high the expression of the signs of heat are reduced, consequently making detection more difficult. Checking cows in holding pens or collecting yards is not to be recommended.

\subsection{Milk yield}

There appears to be a weak antagonistic relationship between milk yield and expression of heat with higher yielding cows showing slightly weaker signs of heat than lower yielding herd mates (see review by Stevenson [21]).

\subsection{Floor surface}

Cows dislike being mounted while standing on concrete and have a preference for softer underfoot surfaces such as grass, dirt or straw bedded yards. Mounting activity was reduced by almost one half when cows were kept on concrete as opposed to softer underfoot conditions while the duration of oestrous activity was reduced by about $25 \%$ [3]. Cows distinctly dislike being mounted by herd mates if the floor surface is either slippery or very coarse.

\subsection{Feet and leg problems}

Cows with sore feet or legs or that have poor structural conformation exhibit less mounting activity and have fewer "stands". Furthermore, such cows may well stand to be mounted when not in heat because it is too painful to escape from the mounting cow. Consequently, lame cows have significantly longer calving to service and calving to conception intervals.

\subsection{Status of herd mates}

The number of cows in heat simultaneously has a major impact on overall heat activity in the herd and on the average number of mounts per cow (Tab. V). The number of mounts per cow increases with the number of cows that are in heat simultaneously up to about 3-4 cows in heat. Thus, in smaller herds and as more cows become pregnant the likelihood of more than one cow being heat on any given day becomes less, consequently, making heat detection more difficult.

Table IV. Percentage of dairy cows first observed in standing heat at specific hours.

\begin{tabular}{lccccc}
\hline Hours & $07: 00$ & $10: 00$ & $13: 00$ & $16: 00$ & $22: 00$ \\
\hline Percent detected & 40 & 5 & 7 & 18 & 30 \\
\hline
\end{tabular}


Table V. Effect of number of cows in heat on mounting activity.

\begin{tabular}{lc}
\hline $\begin{array}{l}\text { Number of cows } \\
\text { in heat simultaneously }\end{array}$ & $\begin{array}{c}\text { Average mounts } \\
\text { per cow in heat }\end{array}$ \\
\hline 1 & 11.2 \\
2 & 36.6 \\
3 & 52.6 \\
$4+$ & 49.8 \\
\hline
\end{tabular}

Source: Hurnick et al. [9].

To be detected in standing heat a cow she must engage the attention of a herd mate willing to mount her. Generally cows that are themselves in heat, coming into heat or were recently in heat are most likely to mount a cow that is in heat. Cows that are at the mid-stages of their cycles (day 5 to about day 16) are least likely to mount a cow that is in heat and consequently could be termed "poor heat detectors". Similarly, cows that are pregnant show less interest in mounting other cows that are in heat. Consequently, as more cows in a herd become pregnant it become increasingly difficult to identify the few remaining open cyclic and repeating cows.

About $10 \%$ of the reasons for failure to detect heats can be attributed to cow problems and $90 \%$ to "management" problems. The latter would include too few observations per day for checking for heat activity, too little time spent observing the cows or observing the cows at the wrong times or in the wrong place such as at feeding time or in the collecting yard at milking time. Another major reason for failure to detect heat is that those involved in heat detection do not understand the signs of heat. To optimise heat detection a number of the signs of heat, both primary and secondary, must be clearly understood.

\section{CRITERIA FOR OESTRUS}

\subsection{Primary signs of heat}

Standing to be mounted by herd mate or bull is the most definite and accurate sign that a cow is in heat. During the period of standing heat, cows stand to be mounted by other cows or move forward slightly with the weight of the mounting cow. Cows that move away quickly when a mount is attempted are in not true heat.

\subsection{Secondary signs of heat}

Because standing heat may not always be observed, stockmen must frequently use other signs of heat in arriving at a decision as to whether or not to inseminate a cow. These secondary signs of heat and may indicate that a cow is coming in heat, in which case closer attention should be given to her over the following 48 hours, or they may be indicative of a recent heat in which case she should be given close attention 17-20 day later.

\subsubsection{Discharge of clear mucus}

This originates in the cervix and uterus and is a good indication of imminent heat. The passing of long clear elastic strings of mucus is indicative of an imminent heat while a thicker cloudier and more viscous mucus is indicative of a recent heat.

\subsubsection{Mounting other cows}

Cattle that mount other animals may be in or approaching heat. Generally, cows that are at the mid-cycle stage of their oestrous cycles or that are in-calf perform mounting activity much less frequently.

\subsubsection{Restlessness}

Signs of restlessness such as increased walking, trailing of other cows and bellowing 
are characteristic of individual cows that are either approaching or are in heat.

\subsubsection{Swelling and reddening of vulva}

Hormonal changes associated with heat cause an increased blood supply to the reproductive organs which in turn causes swelling and reddening of the vulva.

\subsubsection{Hair loss and dirt marks}

As a result of frequent mounting by herd mates, the hair on the tail-head is usually removed and the skin on either side of the tail-head is often scarred and dirty. This is indicative that the cow was recently on heat.

\subsubsection{Blood stains on the tail or vulval area (metoestrous bleeding)}

These are indicative of a recent heat. Such animals should be watched closely for heat 17-20 days later.

\subsubsection{Decreased feed intake and milk yield}

Cows in or approaching heat spend less time feeding. In some studies a drop in milk yield has also been observed. However, because numerous other factors affect milk yield this should not be taken as a reliable sign of heat.

\section{IMPROVING HEAT DETECTION}

The single most important factor affecting heat detection efficiency is that those responsible for checking for heat should fully understand the signs of heat and be fully committed to heat detection for as long as it is planned to use AI.

\subsection{Records}

Individual animal records are an essential part of good breeding management. All animals must be clearly and permanently identified by one of several methods, such as plastic ear tags, neckbands or freeze branding. Whichever system is preferred, it is essential that the animal number be clearly legible from a reasonable distance. Breeding records should include (i) animal number (ii) calving date, and other information relevant to the calving (iii) pre-breeding heat dates (iv) first and repeat service dates and sire used on each date and inseminator code (v) date and result of pregnancy diagnosis and, (vi) date of expected calving. Good records are not only part of good farm management practice but are the first essential step in all infertility investigations.

\subsection{Monitoring submission rate}

This is calculated as the proportion of cows calved at the beginning of the breeding season, that are intended for re-breeding and that are submitted for insemination. A submission rate of at least $80 \%$ should be achieved in the first 21 days of the breeding period. Submission rate, which is easily calculated, is an excellent measure of heat detection rate and should be calculated at the end of the first 21 day period of the breeding season. A submission rate of less than $80 \%$ indicates a problem with heat detection and diagnosis of this problem at such an early stage allows corrective action be taken before much of the breeding period has elapsed.

\subsection{Pre-breeding heat detection}

For seasonally calving herds heat detection should ideally commence 3 weeks before the planned onset of the breeding season. All cows calved 3 weeks before the planned onset of the breeding season should be tail painted and checked 3-times daily until the onset of the breeding season. Cows not observed in heat during this 3-week prebreeding period and, that are more than 42 days calved, should be either selected 
for examination by a veterinary surgeon or identified for special observation during the first 3 weeks of the breeding season. If such cows are not observed in heat during this second 3-week period they should definitely be examined and preferably scanned by a veterinary surgeon to identify the cause of the "apparent" non-cyclicity. The objective is to identify and treat potential problem cows early in the breeding period and thus enhance their chances of being successfully bred.

\subsection{Synchronisation to reduce heat detection}

While methods of controlled or synchronised breeding were developed with the objective of achieving compact calving, they can play an important role in reducing the burden of heat detection. If efficient heat detection is not possible an alternative strategy would be to synchronise all cows calved at least 35 days at the start of the breeding period. Synchronisation allows fixed-time AI without reference to heat. Most of the repeat heats fall over a confined period and can be easily detected. Where calving is compact, about $70 \%$ of cows and all the replacement heifers are available at the start of the breeding season. A synchronised and one repeat insemination should provide adequate herd replacements. Synchronisation procedures for both dairy [5] and beef cows [17] have recently been reviewed. The former study clearly shows that oestrus or ovulation control programmes have significant benefits particularly in herds where existing levels of heat detection are low but have lesser benefits in herds where heat detection rates are already high.

\subsection{Technological aids to improve heat detection}

The low to moderate heat detection efficiencies achieved on most farms reflect the difficulty of detecting heat in cows. While undoubtedly this low detection efficiency is mainly management-related, cow factors also contribute. The latter include the variable signs of heat, the propensity for many cows to show heat from late evening to early morning and the short duration of standing heat all of which add to the difficulty of achieving high heat detection rates. Consequently, it has been and is the goal of many animal science programmes to develop more objective systems to overcome some of the problems of heat detection. An ideal system for detecting oestrus should have the following characteristics [19]: (1) continuous surveillance of the cow; (2) accurate and automatic identification of the cow in oestrus; (3) operation for the productive lifetime of the cow; (4) minimal labour requirements; and (5) high accuracy and efficiency $(95 \%)$ for identifying the appropriate physiological events that correlate with oestrus or ovulation or both. A number of both inexpensive to expensive aids and technologies are available to meet some but not all of these criteria. In any case, use of various technologies to identify symptoms associated with oestrus, ovulation, or both will require judgement of herd management to verify whether or not the cow seems to be in oestrus based on common husbandry experience.

\subsubsection{Tail-painting}

Research from a number of laboratories have shown that applying paint or chalk to the tailhead of cows is effective in indicating standing activity $[7,11,15]$. When such "tail painted" cows are mounted from the rear some or all of the chalk or paint is rubbed off indicating that the painted cows possibly stood in oestrus while mounted by a herd mate. When a cow stands in heat this strip of paint is either partially or totally removed by the mounting animal. Combined with early morning and late evening observations, checks for paint loss at milking times should result in a heat detection rate of close to $90 \%$. Efficiencies of oestrous 
detection using tail paint vary from 44 to $96 \%[11,16,18]$.

\subsubsection{Vasectomised bulls with chin-ball marking harness}

Active vasectomised teaser or detector bulls are useful in identifying cows either coming into or on heat. Vasectomy should be carried out 40-60 days prior to introduction to the herd. Many herds are now finding that teaser bulls are particularly useful after the first 3 weeks of the breeding season when fewer cows are in heat each day and when the level of heat-related activity in the herd is reduced as more cows become pregnant. However, considerable variation in libido exists among bulls and they require the same management as full bulls without conferring any of the advantages. As an alternative to vasectomised bulls cows or heifers treated with testosterone or oestradiol can be useful in detecting cows in oestrus. A full description of hormonal treatments regimens for such females is given by Stevenson [21].

\subsubsection{Pressure activated heat mount detectors}

These devices including these marketed as Kamars, Bovine Beacon and Mate Master are affixed to the tail head of the cow and change colour when pressure is applied by the weight of the mounting animal. Reported efficiencies of heat detection using such heat mount detectors vary from 56 to $94 \%$ while the accuracy of heat detection is reported to vary from 36 to $80 \%$ (see review by Stevenson [21]). The relatively low accuracy of heat detection combined with difficulties in keeping the devices affixed to the tail head limit the potential of this approach.

\subsubsection{Pedometers}

Oestrus in cattle is accompanied by increased physical activity. Cows that are in heat do 2-4 times more walking than a non-oestrous cow. Pedometers can be attached to the leg of the cow to measure the amount of her activity over a unit time span. Earlier pedometric-aided heat detection systems operated with a reported heat detection efficiency of $60-100 \%$ and with an accuracy in the range of 22 to $100 \%$. The low level of accuracy was related to a high proportion of false positives and to technical problems that led to either breakage, malfunction, or loss of the pedometers (see reviews by Lehrer et al. [10], Senger [19], Stevenson [21]). New improved pedometric technology has now led to improved information storage systems, improved analytical capabilities to allow comparison of current with previous physical activity, incorporation of internal power supply to operate the electronics, the development of self-contained devices to interrogate the pedometers in the milking parlour and relay or store information in a personal computer. Some systems have an inbuilt alert system such as a bleeper or flashing light which alerts the farmer when a cow is deemed to be in heat. A number of pedometric systems are commercially available in the US. While scientific information on their operating efficiencies is not yet available these systems would appear to have significant commercial potential.

\subsubsection{Radio telemetric devices}

The primary sign of heat is standing to be mounted. A number of research laboratories have attempted to develop pressure sensitive devices that measure such standing activity. Such a system (HeatWatch; DDX INC, Colorado, USA) is currently commercially available in the US and in a number of other countries. This system involves the location of a pressure sensitive batterypowered transmitter on the cows tail head which, when activated by the mounting cow emits a radio signal which is picked up by either a receiver or repeater (see Fig. 1) and relayed to a buffer and ultimately to a personal computer where the information is 


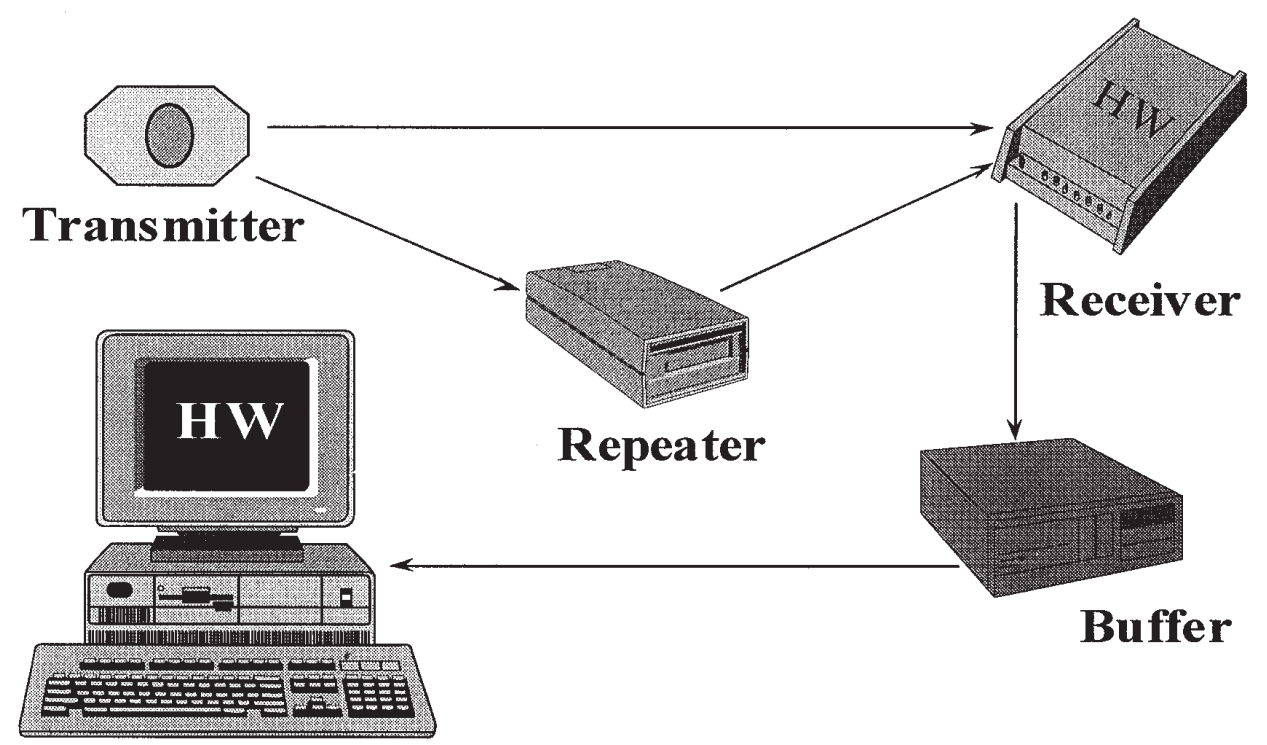

Figure 1. Components of the HeatWatch 24 h oestrus detection system. (Courtesy DDx, Inc.).

digitized and stored. The time, date and duration of each mount along with the identity of each cows is recorded. From this information the time of heat onset is calculated. The HeatWatch software generates management and individual cow reports that can be viewed or printed. HeatWatch classifies a standing heat as a cow having 3 standing events in a four-hour period. A cow with fewer standing events is recorded as a "suspect heat" and such a cow should be checked for secondary signs of heat prior to deciding to inseminate her. Periodically during the day the farmer checks the computer for a listing of cows in heat. The limited data available suggests that HeatWatch operates with both an efficiency and accuracy of almost $100 \%$ in detecting cows in heat $[14,22,27,29]$. The limited data from this laboratory suggests that HeatWatch is an extremely powerful research tool, operates well under both indoor and pasture conditions.

As a lower cost alternative to the complete HeatWatch system DDX have recently launched a system (MountCount) that counts the number of mounts received by a cow in heat. The MountCount is a manual version of the current HeatWatch transmitter. The battery-powered unit is affixed to the tail head of the cow. It contains a pressure switch that is activated when the cow is mounted. When a certain threshold of mounts is reached a light is activated on the device the alerts the farmer that the cow is in heat and should be inseminated. Different flashing light patterns alert the farmer when the cow is in suspect heat, standing heat and when she is considered ideal for breeding.

Yet a further DDX heat detection product also cheaper that the HeatWatch system is HeatWatch Express. This does not need a computer or software to process and display the data. Again like the other DDX systems a small batter-powered radio transmitter is affixed to the tailhead of the cow. The mount data is relayed to a radio receiver and then to a buffer in the farm office from which the data can be printed. The cost of this product is about $\$ 2000$ or about $£ 1700$. 
IMV Technologies in France have also developed a pressure sensitive mount count detector. This system known as DEC is commercially available. The device is programmed in such a way that when a certain number of valid mounts have been recorded a light, incorporated into the DEC, starts to flash. The number of flashes is in proportion to the time elapsed since the first valid mount was recorded. The number of flashes in a 10 -second period indicates the time of heat onset and most appropriate time to inseminate the cow.

\section{REFERENCES}

[1] Adams G.P., Matteri R.L., Kastelic J.P., Ho J.C.H., Ginther O.J., Association between surges of follicle-stimulating hormone and the emergence of follicular waves in heifers, J. Reprod. Fertil. 94 (1992) 177-188

[2] Allrich R.D., Estrous behavior and detection in cattle, Vet. Clin. North Am. Food Animal Practice 9 (1993) 249-262.

[3] Britt J.H., Scott R.G., Armstrong J.D., Whitacre M.D., Determinants of estrous behavior in lac tating Holstein cows, J. Dairy Sci. 69 (1986) 2195-2202.

[4] Coe B.L., Allrich, R.D., Relationship between endogenous estradiol-17 $\beta$ and estrous behavior in heifers, J. Anim. Sci. 67 (1989) 1546-1551.

[5] Diskin M.G., Sreenan J.M., Roche J.F., Controlled breeding systems for dairy cows, in: Diskin M.G. (Ed.), Proc. BSAS Occasional Meeting: Fertility in the High-Producing Dairy Cow (in press).

[6] Dransfield M.G.B., Nebel R.L., Pearson R.E., Warnick L.D., Timing of insemination for dairy cows identified in estrus by a radiotelemetric estrus detection system, J. Dairy Sci. 81 (1998) 1874-1882.

[7] Foote R.H., Estrus detection and estrus detection aids, J. Dairy Sci. 58 (1975) 248-256.

[8] Gordon I., Controlled breeding in cattle. Part 1. Hormones in the regulation of reproduction, oestrous control, and set time artificial insemination, Anim. Breed. Abstr. 44 (1976) 265-275.

[9] Hurnik J.F., King G.J., Robertson H.A., Estrous and related behaviour in postpartum Holstein cows, Appl. Anim. Ethol. 2 (1975) 55-68.

[10] Lehrer A.R., Lewis G.S., Aizinbud E., Oestrus detection in cattle: recent developments, Anim. Reprod. Sci. 28 (1992) 355-361.
[11] Macmillan K.L., Curnow R.J., Tail painting - a simple form of oestrus detection in New Zealand dairy herds, N. Z. J. Exp. Agric. 5 (1977) 357-361.

[12] Mawhiney S. Roche J.F., Effect of suckling and environmental changes on oestrous behaviour in cattle, Ir. J. Agric. Res. 19 (1980) 2456-2531.

[13] Mulvehill P.G., Studies related to the induction and control of oestrus and ovulation in the bovine, Ph.D. thesis, National University of Ireland, Dublin, 1977.

[14] Nebel R.L., Walker W.L., Kosek C.L., Pandolfi S.M., Integration of an electronic pressure sensing system for the detection of estrus into daily reproductive management, J. Dairy Sci. 78 (Suppl. 1) (1995) 225.

[15] O'Farrell K.J., Fertility management in the dairy herd, Ir. Vet J. 34 (1980) 160-169.

[16] Pennington J.A., Albright J.L., Callahan C.J., Relationships of sexual activities in estrous cows to different frequencies of observation and pedometer measurements, J. Dairy Sci. 69 (1986) 2925-2934.

[17] Roche JF, Austin E.J., Ryan M., O’Rourke M., Mihm M., Diskin MG., Regulation of follicle waves to maximize fertility in cattle, J. Reprod. Fertil. Suppl. 54 (1999) 61-71.

[18] Sawyer G.J., Russell-Brown I.D., Silcock J.K., A comparison of three methods of oestrus detection in commercial dairy herds verified by serum progesterone analysis, Anim. Reprod. Sci. 10 (1986) 1-10.

[19] Senger P.L., The estrus detection problem: New concepts, technologies, and possibilities, J. Dairy Sci. 77 (1994) 2745-2753.

[20] Stagg K., Spicer L.J. Srenan J.M., Roche J.F., Diskin M.G., Effect of calf isolation on follicular wave dynamics, gonadotrophin and metabolic hormone changes, and interval to first ovulation in beef cows fed either of two energy levels postpartum, Biol. Reprod. 59 (1998) 777-783.

[21] Stevenson J.S., A review of oestrous behaviour and detection in dairy cows, in: Diskin M.G. (Ed.), Proc. BSAS Occasional Meeting: Fertility in the High-Producing Dairy Cow (in press).

[22] Stevenson J.S., Lamb G.C., Kobayashi Y., Hoffman D.P., Luteolysis during two stages of the estrous cycle: Subsequent endocrine profiles associated with radiotelemetrically detected estrus in heifers, J. Dairy Sci. 81 (1998) 2897-2903.

[23] Stevenson J.S., Smith M.W., Jaeger J.R., Corah L.R., LeFever D.G., Detection of estrus by visual observation and radiotelemetry in peripubertal, estrus-synchronized beef heifers, J. Anim. Sci. 74 (1996) 729-735. 
[24] Sunderland S.J., Crowe M.A., Boland M.P., Roche J.F., Ireland J.J., Selection, dominance and atresia of follicles during the estrous cycle of heifers, J. Reprod. Fertil. 101 (1994) 547-555.

[25] Trimberger G.W., Breeding efficiency in dairy cattle from artificial insemination at various intervals before and after ovulation, Res. Bull. Nebraska Agricultural Exp. 153 (1948) 26 p.

[26] Vailes L.D., Washburn S.P., Britt J.H., Effects of various steroid milieus or physiological states on sexual behavior of Holstein cows, J. Anim. Sci. 70 (1992) 2094-2103.
[27] Walker W.L., Nebel R.L., McGilliard. Time of ovulation relative to mounting activity in dairy cattle, J. Dairy Sci. 79 (1996) 1555-1561.

[28] Woody C.O., First N.L., Pope A.I., Effect of exogenous progesterone on oestrous cycle length in cattle, J. Anim. Sci. 24 (1965) 139-141.

[29] Xu Z.Z., McKnight D.J., Vishwanath R., Pitt C.J., Burton L.J., Estrus detection using radiotelemetry or visual observation and tail painting for dairy cows on pasture, J. Dairy Sci. 81 (1997) 2890-2896. 
